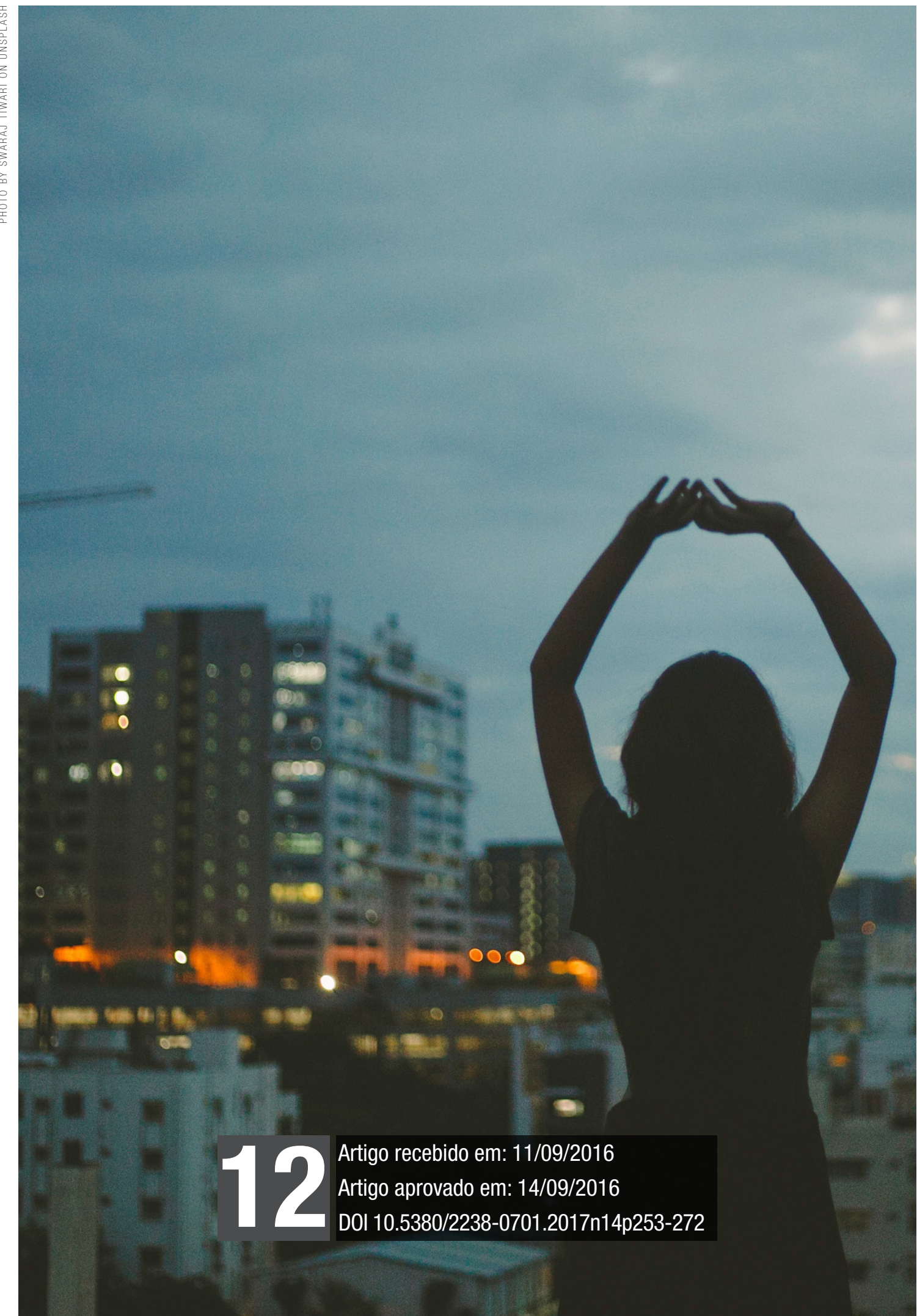


Consumo. Yoga. Experiências etnográficas. 


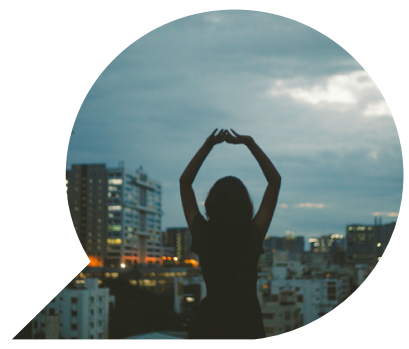

\section{O consumo de yoga a partir de experiências etnográficas}

\section{The consumption of yoga from ethnographic experiences \\ El consumo de yoga a partir de experiencias etnográficas}

\begin{tabular}{c}
\hline FILIPE BORDINHÃO DOS SANTOS \\
\hline ANNA TROIB PENTEADO \\
\end{tabular}

Resumo: $\mathrm{O}$ trabalho discute as experiências de consumo do método Kaiut Yoga a partir de uma perspectiva antropológica do consumo, sobretudo para compreender como o produto cultural (e mercadológico) da Yoga promove rituais e valores simbólicos que extrapolam a relação produto-preço e se inserem como prática social de interação. Para isso, realizamos aproximações etnográficas na escola Kaiut Yoga através das técnicas de observação participante e entrevistas com os alunos. Dessa forma, entendemos os valores culturais e intagíveis que permeiam o processo de consumo deste produto, especialmente os que dizem respeito às formas de relacionamento com o outro, o convívio em uma comunidade e a experiência de consciência de si mesmo a partir do consumo como ritualístico e mediador social.

Palavras-chave: Consumo; Kaiut Yoga; Experiências Etnográficas.

\footnotetext{
* Doutor em Comunicação. Coordenador da Especialização em Comportamentos de Consumo e professor dos Cursos de Jornalismo e Publicidade e Propaganda da Universidade Positivo (UP), Curitiba/ PR. E-mail: filipe.santos@up.edu.br

** Graduada em Comunicação Institucional pela Universidade Tecnológica Federal do Paraná e especialista em Comportamentos de Consumo (UP). Redatora da Circo de Propaganda e Pesquisadora em Autem Solutions. E-mail: annapenteado@gmail.com.
} 


\begin{abstract}
The paper discusses the experiences of consumption of the Kaiut Yoga method from an anthropological perspective of consumption, especially to understand how the cultural (and market) product of Yoga promotes rituals and symbolic values that extrapolate the product-price relationship and fit into practice Social interaction. For this, we carry out ethnographic approaches in the Kaiut Yoga school through participant observation techniques and interviews with the students. In this way, we understand the cultural and intangible values that permeate the consumption process of this product, especially those that relate to the forms of relationship with the other, the community in a community and the experience of self-awareness from consumption as ritualistic and social mediator.
\end{abstract}

Keywords: Consumption; Kaiut Yoga; Ethnographic Experiences.

Resumen: El trabajo discute las experiencias de consumo del método Kaiut Yoga desde una perspectiva antropológica del consumo, sobre todo para comprender cómo el producto cultural (y mercadológico) del Yoga promueve rituales y valores simbólicos que extrapolan la relación producto-precio y se insertan como práctica Social de interacción. Para ello, realizamos aproximaciones etnográficas en la escuela Kaiut Yoga a través de las técnicas de observación participante y entrevistas con los alumnos. De esta forma, entendemos los valores culturales e inigualables que permean el proceso de consumo de este producto, especialmente los que se refieren a las formas de relación con el otro, la convivencia en una comunidad y la experiencia de conciencia de sí mismo a partir del consumo como ritual $y$ mediador social.

Palabras clave: Consumo; Kaiut yoga; Experiências etnográficas. 


\section{Introdução}

Para compreender o consumo cultural dos alunos da escola Kaiut Yoga, no que diz respeito aos fatores intangíveis da experiência prática, adotamos uma perspectiva sociológica e antropológica do consumo, a fim de identificar as relações com os valores sociais e simbólicos inseridos neste espaço de convivência e consumo. Para tanto, o presente trabalho realizou uma pesquisa exploratória, a partir de experiências etnográficas, aqui separada em duas etapas - bibliográfica e qualitativa; sobretudo por meio das técnicas de observação participante e conversas informais articuladas com o questionário online - com perguntas fechadas e abertas.

$\mathrm{Na}$ primeira etapa buscou-se o aprofundamento nas questões culturais do consumo e seus rituais. A cultura é um abrigo para as necessidades interpretativas do presente e constrói a realidade do homem racional, demandada por estruturas lógicas e significadas. Procurou-se entender se esse consumidor que pratica yoga para buscar equilíbrio e a cura da dor (consumo do serviço), também se sente identificado e acolhido em um ambiente confortável em que ele tem um grupo, um líder, rituais periódicos e uma cultura (consumo cultural).

Com isso, faz-se essencial explorar os valores simbólicos dos rituais da prática da Kayut Yoga e examiná-los a partir dos estudos da antropologia do consumo. Além do próprio ritual de consumo, pode-se notar quão ritualístico é o método Kaiut de yoga e quão necessário é explorar seus ritos e significados para que haja não apenas o consumo cultural deste produto, mas também o convencimento do consumidor com um serviço que traz um universo de experiências para o sujeito.

\section{Consumo cultural}

Entendemos o consumo além da usual noção economiscista que visa somente compreendê-lo a partir de uma esfera mercadológica. A ideia de dimensão simbólica do consumo como prática de representação das estruturas de significação da sociedade capitalista, surgiu a partir de estudos dos autores Bourdieu e Baudrillard. Esta visão propõe que, não só se consome a materialidade dos objetos, como também, os significados gerados por valores sociais compartilhados. 
O consumo é um modo ativo de relação (não apenas com os objetos, mas com a coletividade e com o mundo), um modo de atividade sistemática e de resposta global em que se funda todo o nosso sistema cultural [...]. O consumo, pelo fato de possuir um sentido, é uma atividade de manipulação sistemática de signos (BAUDRILLARD, 1997, p. 206).

Nesta direção, García-Canclini (1995) define o consumo como conjunto de processos socioculturais em que permeiam a apropriação e os usos dos produtos. Para o autor, grande parte da racionalidade das relações sociais se constroi pela disputa em relação à apropriação dos meios de distinção simbólica e isso se correlaciona com a construção dos signos de status nas sociedades contemporâneas. A distinção é produto da identificação, assim como a identificação também é produto dessa diferenciação, observa-se, então, como o consumo é cultural e influencia as referências e normas de pertencimento com determinados hábitos culturais. $\mathrm{O}$ autor denomina essa construção como racionalidade integrativa e comunicativa de uma sociedade (GARCÍA-CANCLINI, 1995), a qual iremos nos alinhar para entender o consumo do objeto de estudo.

Nota-se uma uniformidade nos hábitos de indivíduos de um mesmo grupo ou classe social - "estudam, habitam, passam as férias, naquilo que leem e desfrutam, em como se informam e no que transmitem aos outros" (GARCÍA-CANCLINI. 1995, p. 62). Pode-se reconhecer que o sistema mercadológico é composto por um espaço de interações socioculturais complexas e a visão antropológica do consumo manifesta-se para entender esse universo de símbolos e signos que nascem de diversas perspectivas de cenários coletivos, ou seja, o consumo adquire um status cultural a partir do momento que se estabelece no contexto social não apenas a partir de bens físicos, mas de práticas e incorporações identitárias.

Segundo Karsaklian (2000), além da estrutura social em que o indivíduo está imerso, há os grupos de referência - família, escola, trabalho, clube - que também o afetam a partir de circunstâncias e pressões que modelam o seu comportamento com relação ao coletivo. Por causa disso, indivíduo pode se diferenciar subjetivamente e, ao mesmo, o consumo pode ser um fator integrador, isto é, um espaço e/ou ato socializador.

Finalmente, a sociedade na qual vive o consumidor não existe no vácuo e está, ela mesma, inserida em algo mais amplo e também padronizador comportamental que conhecemos pelo nome de cultura. A cultura vai determinar as normas e valores que devem ser seguidos e respeita- 
dos pelos indivíduos, o que significa que, de uma cultura para outra, diferenças de comportamento com relação aos mesmos objetos são facilmente verificadas (KARSAKLIAN, 2000, p.12).

Os elementos pessoais que um indivíduo carrega consigo são, no entanto, inerentes à sua individualidade, pois ele também é um ser social e está inserido em grupos que lhe servem como referência. Apesar da autora referenciada ser da área do marketing, percebe-se uma aproximação com uma perspetiva sociológica a medida que reconhece fatores sociais e subjetivos formados ao longo da vida do sujeito que, por sua vez, são responsáveis por demarcarem as práticas de consumo.

Nessa perspectiva, assemelha-se ao conceito de mediações de Martín-Barbero (2006), em que o autor sugere a existência de três mediações transformadas em dimensões - sociabilidade, ritualidade, tecnicidade (RONSINI; SILVA; WOTTRICH, 2009). Os sentidos e modos de uso social do discurso comunicacional que permeiam a construção e desconstrução do individual e do coletivo estão inteiramente correlacionado com a socialidade, isto é, a mediação formativa é responsável por gerar as motivações na busca do sujeito pelo método de yoga. Alicerçados pelas Matrizes Culturais, os indivíduos "ativam e moldam os habitus que conformam as diversas Competências de Recepção" (MARTÍN-BARBERO, 2006, p. 17). Portanto, pode-se afirmar que são os contextos dos sujeitos - histórico, social de formação e de convivência - que os norteiam e os definem, bem como, sugerem comportamentos e posicionamentos na esfera do consumo de bens e mídias.

Além disso, a representação social e todo seu universo simbólico permeiam o processo de consumo, aqui entendido, justamente, como práticas cotidianas que envolvem relações sociais articuladas através de representações sociais. Para Moscovi (1978, p.45), as representações possuem uma dupla dimensão de sujeito e sociedade, situando-se no limiar de conceitos sociológicos e psicológicos, portanto, devem ser julgadas "tanto na medida em que ela possui uma contextura psicológica autônoma como na medida em que é própria de nossa sociedade e de nossa cultura".

Neste sentido, Douglas e Isherwood $(1979,1996)$ compreendem que os indivíduos se relacionam com o objeto de consumo a partir dos valores, significados e sentimentos que eles aferem a esse bem e seus rituais. Segundo os autores, com o olhar da antropologia, o consumo é visto como uma prática coletiva e ritualística fixada em significados sociais que, por sua vez, promovem o ajustamento do indivíduo ao meio social. 
Deve-se também contextualizar que foi a partir dos anos 1960, com as contraculturas advindas da juventude da época - também responsáveis pelo movimento hippie nos EUA - que deu-se o início a uma posição antitecnológica em relação à saúde, despertando um interesse crescente da cultura oriental pelos cidadãos urbanos ocidentais (CAMPBELL, 1997). Especialmente ligado à busca pela sensação de bem-estar por meio das terapias orientais - como, por exemplo, a prática da meditação budista e da yoga, desde o fim do século XX.

Despojados de su sentido tradicional, de su sentido sagrado, los cuerpos consumen estas técnicas entrando sin quererlo, en la lógica del mercado transnacional. Esta es la imagen del sujeto, eficiente, armonioso y espiritual [...]. El increíble torrente de imágenes proporcionada por los medios promueven de forma activa este estilo de vida eficiente y saludable alimentando una imagen de mercado donde se combina la estética y la salud. Fitness and Health el nuevo lema de mercado que parece generar una sensación de confianza en los consumidores [...]. (PULIDO, 2009, p.46)

Como consequência, a cultura passa a ser vista não apenas como um produto cultural, mas também ganha espaço para se tornar um serviço que oferece conforto e bem-estar espiritual para as pessoas. Isso se justifica, especialmente, por causa da necessidade que as pessoas passam a ter por bens e serviços terapêuticos, como uma forma alternativa de superar as tensões e dissabores da vida contemporânea. Fato que abre espaço para um promissor mercado fitness e wellness ${ }^{1}$, e da própria saúde alternativa, a partir das últimas décadas, sobretudo por incentivo da publicidade e da mídia - o que fica mais evidente atualmente com as redes sociais digitais.

\section{O consumo como ritual}

Além do próprio ritual de consumo - visando que a prática de yoga é um ato de consumo pode-se notar quão ritualistico é o método Kaiut de yoga e quão necessário é explorar seus ritos e significados a partir da compreensão das definições de rituais. Peirano (2003) descreve

\footnotetext{
${ }^{1}$ A popularização do conceito de bem-estar durante os anos 1970 e 1980 levou à propagação de programas de bem-estar em grandes corporações, bem como, o desenvolvimento de programas pelo governo para promover estilos de vida mais saudáveis (EUA). Teorias sobre vida saudável, auto-ajuda, bem-estar, fitness, dieta e espiritualidade continuam proliferando hoje. (Stanford Research Institute, 2010)
} 
o ritual, referenciando Stanley Tambiah - como "um sistema cultural de comunicação simbólica. Ele é constituído de sequências ordenadas e padronizadas de palavras e atos, em geral expressos por múltiplos meios". Pode-se, também, dialogar com as questões culturais de Stuart Hall (2003). O autor observa que "na experiência todas as práticas se entrecruzam, dentro da cultura todas as práticas interagem ainda que de forma desigual e mutuamente determinante". Além disso, sobre os epítetos utilizados nas práticas do Kaiut Yoga, pode-se correlacioná-los com o que o autor disserta sobre a importância crucial da linguagem e da metáfora linguística como fonte de identidade.

Para qualquer estudo da cultura; a expansao da nocao do texto e da textualidade, quer como fonte de significado, quer como aquilo que escapa e adia o significado; o reconhecimento da heterogeneidade e da multiplicidade dos significados, do esforco envolvido no encerramento arbitrário da semiose infinita para além do significado; o reconhecimento da textualidade e do poder cultural, da propria representação, como local de poder e de regulamentacao; do simbólico como fonte de identidade. (HALL, 2003, p.211)

Sobre significações, Douglas e Isherwood (1979, 1996), estabelecem que os significados são abstratos e fluidos, portanto, para contê-los e estabilizá-los, dá-se a importância de definir rituais por meio de convenções social, pois "viver sem rituais é viver sem significados claros e, possivelmente, sem memórias. Alguns rituais puramente verbais, vocalizados, não registrados; desaparecem no ar e dificilmente ajudam a restringir o âmbito da interpretação. (p.110).

Com base nos pensamentos dos autores supracitados, García-Canclini (1995) complementa que os rituais tornam as definições públicas perceptívas e mais compreensivas a partir de um consenso geral e coletivo do que um grupo julga valioso. Segundo o autor, o consumo é como um processo ritual, cuja função primária consiste em dar sentido ao fluxo rudimentar dos acontecimentos e é, em consequência disso, que muitos bens são consumidos como acessórios rituais. Além disso, o ato de consumir está diretamente interligado com a insatisfação do fluxo transviado dos significados e que "consumir é tornar mais inteligível um mundo onde o sólido se evapora" (GARCÍA-CANCLINI, 1995, p. 64).

Em vista disso, faz sentido recorrermos a ideia de Bauman (2008) o qual defende que a sociedade passou por uma transição de Sólido-Moderna de produtores - que apostava na prudência, na durabilidade e na 
segurança em longo prazo - para uma sociedade Líquido-Moderna de consumo - impregnada pela necessidade crescente da satisfação imediata de necessidades e desejos crescentes. Com esse ruir das instituições de referência do sujeito, há cada vez mais indivíduos buscando outras formas de identificação e construção identitária baseados em consumo e na mídia. Contrapondo o pessimismo de Bauman, sabe-se que o sujeito ainda tem nas suas bases formativas uma ancoragem territorial (MARTÍN-BARBERO, 2004), já que é no território local que acontece a vida cotidiana e a temporalidade da ação coletiva, que constrõem relatos e imagens de identidade.

Quando definimos o método, nós não partimos de um único indivíduo, partimos de uma coletividade, de uma experiência, de um teste, e chegamos a uma conclusão que vai servir a todos os indivíduos enquanto forma, porque todos nós somos seres humanos, somos bípedes e todos nós envelhecemos. Essa é a tríade de conhecimento, de desafio, que pressupõe a existência desse método enquanto uma necessidade, para que os corpos de hoje, que lidam com cadeiras, carros, aviões e condições inimagináveis há 100 anos (não estou falando de 2000 anos, só de 100 anos atrás), possam se beneficiar do mesmo Yoga que foi produzido, escrito, codificado a centenas de anos. Este para mim foi o desafio. (SITE DA KAYUT/MÉTODO, 23/06/2017).

Apesar da prática de Yoga ser um processo de consumo coletivo, é claro que o público alvo do método Kaiut são indivíduos com vazios, dores e contextos pós-modernos. Bem como, é inegável que o consumismo se tornou central para a sociedade e preenche um papel importante na autoidentificação individual e coletiva, bem como, trata-se de um traço da construção da identidade do sujeito pós-moderno e fluido. Bauman (2008) esboça o consumismo como uma ordem social sob efeito da reciclagem das vontades, desejos e anseios humanos em regime social pré-estabelecido. Esses tornam-se sentimentos de propulsores da sociedade e são protagonistas nos processos de identidade do indivíduo vazio e fluído.

No entanto, também é válido considerar a perspectiva de GarcíaCanclini (1995) de que o consumo também serve para pensar e que mesmo diante do suposto caos pós-moderno, o indivíduo ainda possui suas próprias referências de formação que o ancoram e o orientam em suas práticas de consumo. 
Algumas correntes do pensamento pós-moderno têm chamado a atenção em uma direção oposta à que estamos sugerindo - sobre a disseminação do sentido, a dispersão dos signos e a dificuldade de estabelecer códigos estáveis e compartilhados. Os cenários do consumo são invocados por esses autores como lugares onde se manifesta com maior evidência a crise e a racionalidade moderna e seus efeitos sobre alguns princípios que haviam regido o desenvolvimento cultural. (GARCÍACANCLINI. 1995, p. 63).

Ainda sobre a relação dos indivíduos com o consumo, entendese como útil também a mediação da ritualidade proposta por Martín -Barbero (2006) - pois estamos tratando de uma relação com um bem cultural que também envolvem ritualizações midiáticas. Os valores reconhecidos e incorporados pelos indivíduos também fazem parte no momento de significação dos bens materiais e simbólicos. O "nexo simbólico que sustenta toda a comunicação: à sua ancoragem na memória, aos ritmos e formas, seus cenários de interação e repetição" (MARTÍN-BARBERO, 2006, p.19). O autor também afirma que a ritualidade atua como uma "gramática da ação", ou seja, ela interfere nos modos de interpretação e interação dos atores no processo de consumo, bem como, regula a interação do tempo e espaço dos meios com a rotina dos indivíduos. Além disso, essa gramática envolve a motivação do sujeito na busca por uma autorealização e protocolos de práticas de consumo no momento de uso do método.

\section{Aspectos metodológicos}

A pesquisa antropológica é realizada a partir do método de observação com uma visão deslocada do pesquisador para uma outra cultura. Para embasar o olhar etnográfico desse método, o presente artigo apresenta a perspectiva de François Laplantine, cujas linhas de pesquisas são antropologia médica, antropologia das religiões, oralidade e textualidade, mestiçagem.

Laplantine (2004, p.18) determina certos príncipios para uma pesquisa etnográfica, como conhecer o campo, ver e olhar - significação das variantes -, realizar uma "descrição nem desenvolta, nem solta" e, principalmente, sensibilidade sensorial e comportamental do pesquisador. A partir desses regimentos, houve uma aproximação empírica de participação e observação nos grupos de prática do método Kaiut de yoga, para uma percepção mais íntima das entrelinhas e intangibilidades dessa atividade. 
Para isso, inicialmente, utilizou-se da técnica de observação participante - ou seja, a pesquisadora se inseriu in loco para observar o consumo do método, durante os meses que participava como aluna - de outubro/2016 a abril/2017 -, duas vezes por semana. Sabendo da complexidade do método etnográfico, ressaltamos que esse estudo trata-se apenas de experiências etnográficas, ou seja, relatos das primeiras incursões no campo de estudo. Por isso, referimo-nos a um estudo de caráter exploratório sobre o consumo do método Kaiut de yoga.

[...] a observação participante não só pode abarcar estudos de recepção de mensagens da televisão ou de outros meios, caráter massivo ou comunitário, mas também estar interessada em captar outros processos comunicacionais, tais como: sistema de gestão de um meio comunitário de comunicação, mecanismos de participação popular na programação, bastidores dos momentos de produção de uma telenovela, modalidades de comunicação grupal, tipos de relações e interferências num departamento de produção jornalística, relações entre pares e idiossincrasias num departamento de criação em agência de publicidade (PERUZZO, 2003, p. 136).

Além disso, e de forma complementar, foi elaborado um questionário para coletar dados preliminares e exploratórios sobre a relação do indivíduo com o produto cultural (e serviço) em questão. Esta é a uma técnica de coleta de informação quantitativa, que favorece o delineamento do perfil dos informantes, assim como a sua organização com perguntas iguais facilita o processo de tabulação. Sendo assim, "o questionário estruturado, muitas vezes, é utilizado para dar subsídio inicial ou para aprofundar resultados obtidos em entrevistas em profundidade" (DUARTE, 2006, p.67) ou, no nosso caso, na observação participante. O roteiro utilizado para a pesquisa foi dividido em quatro eixos base: fatores intangíveis da prática, identificação dos valores simbólicos e a relação com o contexto social, a motivação e, por fim, a percepção do ritual de consumo.

Os participantes da pesquisa foram selecionados por frequentarem a sede principal da Kaiut Yoga, na cidade de Curitiba, e são de idades e sexos variados. A seleção da amostra dos consumidores foi realizada por julgamento, pois o objeto de estudo encontra-se em um grupo social segmentado e ainda restrito. É importante destacar que a aplicação foi direcionada devido ao método da yoga ser um produto bastante específico e de criação recente. 
Houve um primeiro contato com esses participantes por conversas informais via Facebook e telefone. A partir disso, os questionários foram realizados por meio de formulários online, da plataforma Wufoo - Survey Monkey -, em duas etapas, em um primeiro momento com perguntas que traçam um perfil básico do consumidor e, numa segunda etapa, foram realizadas perguntas abertas, para compreender a relação deles com o produto cultural - o método. Essa etapa da pesquisa ocorreu entre 14 a 20 de julho de 2017 e teve como objetivo a possibilidade de extrair e explorar as motivações, crenças, atitudes e sentimentos as impressões dos consumidores sobre a experiência de consumo da prática do Kaiut Yoga.

\section{O método Kaiut de yoga}

Foi pensando em uma yoga praticada sem lesões que Francisco Kaiut, desenvolveu - a partir de posições clássicas e com referências no Hatha Yoga - o seu próprio método de ensino. Cada sequência de aula é planejada anteriormente partindo de princípios energéticos, biomecânicos e fisiológicos e com foco maior às dores e dificuldades individuais, por isso os professores fazem ajustes para cada aluno. Além disso, o método Kaiut Yoga usa movimentos que trabalham a permanencia de posições, também para preservar o corpo.

$\mathrm{Na}$ apresentação do método - sites, revistas, entrevistas, divulgação interna, redes sociais, etc - a preocupação com a saúde do corpo aparece como foco principal da Kaiut Yoga. O discurso do método, é sempre carregado pela busca da cura da dor, do envelhecimento do corpo e pelo equilíbrio espiritual, e é proferido e convencionado durante todo o ato de consumo deste serviço, por seu criador, pelos professores da Kaiut e secretárias.

O criador e disseminador do método Kaiut, Francisco, começou a se interessar pela Yoga devido a um trauma causado na infância - um tiro no quadril, aos 6 anos. Posteriormente, se especializou em massagem terapêutica e quiropraxia. Nos anos 1990, tornou-se um terapeuta muito requisitado em Curitiba e, na mesma década, começou a se especializar com frequência no exterior, enriquecendo e desenvolvendo cada vez mais seu método. Hoje, além da sede em Curitiba, onde ele é o professor principal - e figura de liderança -, também ministra cursos de iniciação ao Método Kaiut no Brasil, Europa, EUA e América Latina. 


\section{Imagem 1: Francisco em aula.}

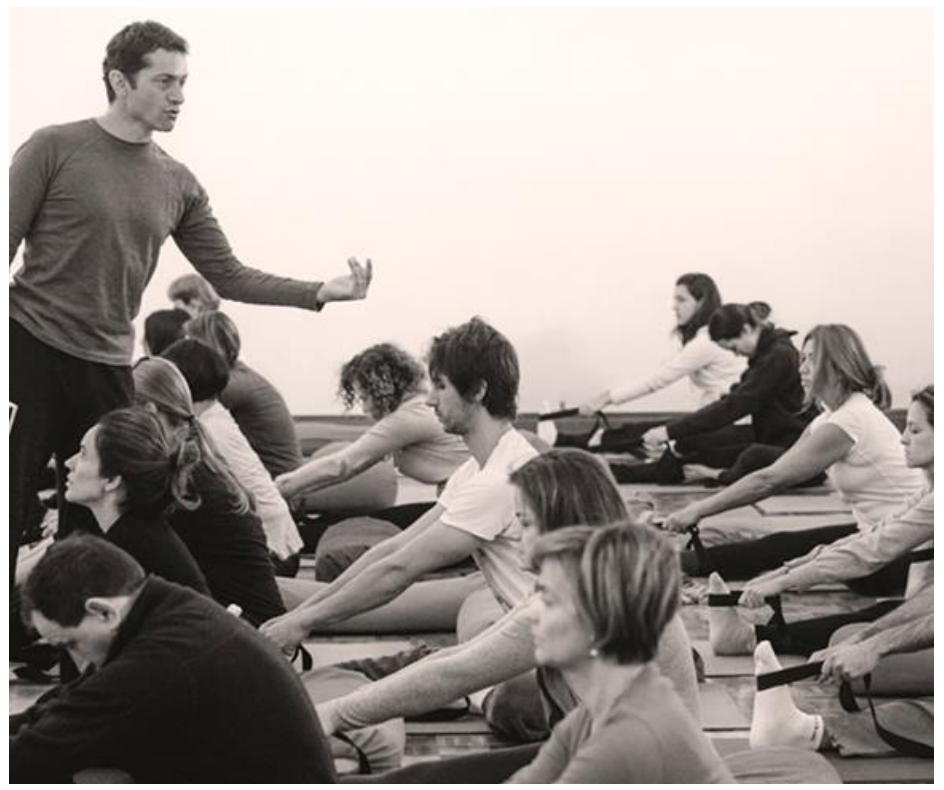

Fonte: http://kaiutyoga.com.br/site/

\section{Experiência etnográficas sobre o consumo do Kaiut Yoga}

Ao primeiro contato com o espaço, há um atendimento atencioso e personalizado, com direito à consulta com um dos professores e, já nas primeiras aulas, há um acompanhamento intenso até a adaptação às posições, materiais, saus nominações - ao método. A partir das aulas seguintes, alicerçado pela ritualização, há uma inclusão à lógica da imitação, da concentração nos movimentos, da repetição e da permanência, ou seja, da experiência com um novo universo de experimentações e conhecimentos.

Entrando no universo das práticas do Kaiut Yoga, elas iniciam com a voz de comando do professor da turma, que pede para seus alunos "entrarem" em alguma posição "yogue", para que mudem a respiração e "abram as suas práticas" - esse início é claramente um momento de imersão na prática. Essa voz lidera a turma nos próximos passos desse ritual até o fim, estágio que também é marcado por um exercício de relaxamento, respiração e imersão em uma ambientação de luz baixa. 
Imagem 2: Sala principal

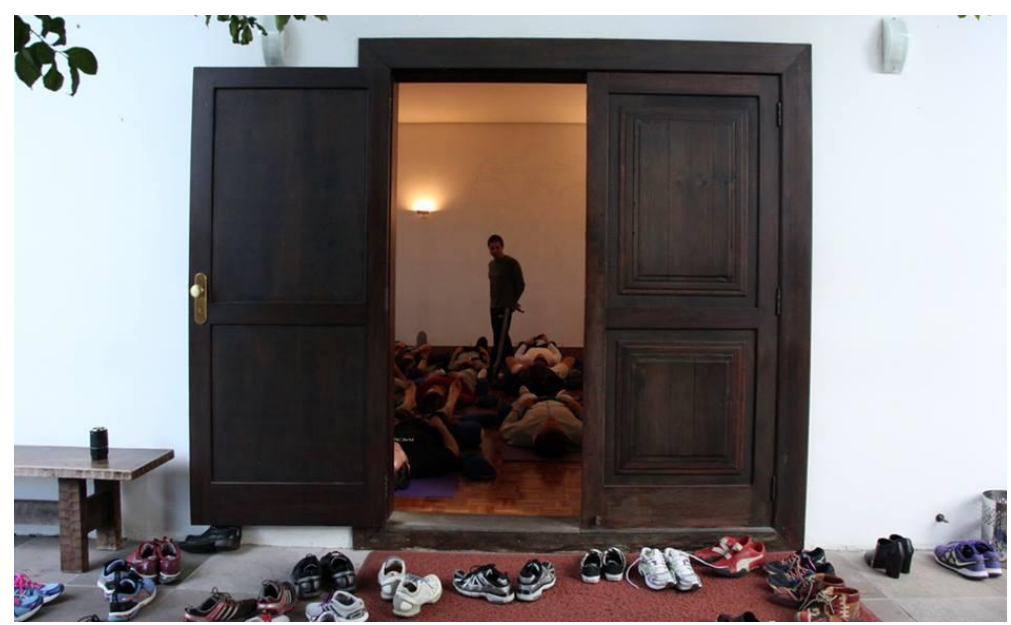

Fonte: http://kaiutyoga.com.br/site/)

Na prática, o professor é o lider - aquele sujeito capaz de orientar as práticas de consumo simbólico por meio do uso do método de yoga. Todo o indivíduo que compõe a sociedade é membro de algum grupo, bem como, ocupa certas posições, e em cada uma delas encontram-se conjuntos de comportamentos que nelas se correspondem. Karsaklian (2000) aponta que, em geral, nos grupos alguns indivíduos estariam em privilégio, estes são os líderes de opinião. $\mathrm{O}$ indivíduo líder é naturamente percebido e seguido pelos demais. Na coletividade da Kaiut Yoga, Francisco, o criador do método - também professor das turmas "avançadas” - é claramente um líder que agrega questões simbólicas ao método, especialmente a partir da sua experiência de vida como forma de gerar a identificação dos consumidores e, portanto, um fator integrativo para o consumo.

Como em qualquer prática de yoga as posições tem nomes específicos e são citados repetidamente por essa voz líder para seus discípulos, que desde o ínicio são ensinados a saberem que, por exemplo, em um vīrāsana ${ }^{2}$ o sujeito deve se ajoelhar e sentar sobre os pés. Douglas e Isherwood $(1979,1996)$, identificam o compartilhamento de nomes inclusive a alegria de identificá-los - como uma recompensa de um lon-

${ }^{2}$ Vĩrāsana surgiu nas práticas de meditação do Hinduísmo, o que significa sentar-se sobre as pernas juntas. 
go investimento de tempo e dinheiro, que entram na coleção de "prova" desse indivíduo consumidor e dos demais que também os classificam e desfrutam e co-participam dessa cultura.

Após alguns meses de práticas consegue-se reparar que a auto-observação ocorre a partir das sensações corporais ocasionadas pelas longas permanências em posições - muitas vezes incômodas-, seguidas por posições de relaxamentos. Inclusive, a forma como se emprega a prática da meditação (origem budista) aos finais das aulas, tem claramente o intuito de fazer com que os praticantes sintam o corpo e tenham uma maior consciência dele e de si.

A partir de relatos coletados pelas conversas informais e pelo questionário, sobretudo nas perguntas qualitativas, um ponto comum a todos, é o interesse pela uma evolução físico-mental pela prática do método da Kaiut Yoga - o que, segundo o líder, fora alcançado por ele. Outro quesito que desponta entre os pesquisados é cura, seja da dor, da ansiedade e/ou stress, principalmente como motivação, apesar de ter um relato em que a terapêutica do método aparece como identificação. Isso reforça a questão do consumo simbólico, como também um fator construtor da identidade e satisfação pessoal.

Quando os participantes foram questionados se havia alguma simbologia na prática que chamava atenção, Vera (58 anos), Luciana (26 anos) e Leandro (20) responderam que não e, na perspectiva de Guilherme (28 anos): "Acho que a principal simbologia que percebo é o aspecto clean de todo o método, durante as aulas as práticas não são focadas simbolismo característico do yogi". Com um olhar para as entrelinhas, pode-se reparar que pelo método ser contemporâneo - criado há 25 anos - e por não manter o foco em seguir o tradicional yoga, percebe-se uma nebulosidade sobre o tópico em questão.

Entretanto, há relatos sobre a conexão com valores intagíveis da prática: "apesar de não ter símbolos, músicas e outros sons que remetem ao espiritualismo, sempre consigo me conectar" (Vera, 58 anos) e "eu gosto da ligação com a consciência, não apenas do corpo mas da mente, da introspecção" (Carmem, 62 anos). Com isso, vimos quão o consumo simbólico traz a possibilidade de conciliar essa proposta de produto cultural como a necessidade contemporânea que as pessoas buscam satisfazer - resgatar os vínculos, superar a materialidade das coisas. 
Imagem 3: Francisco em aula

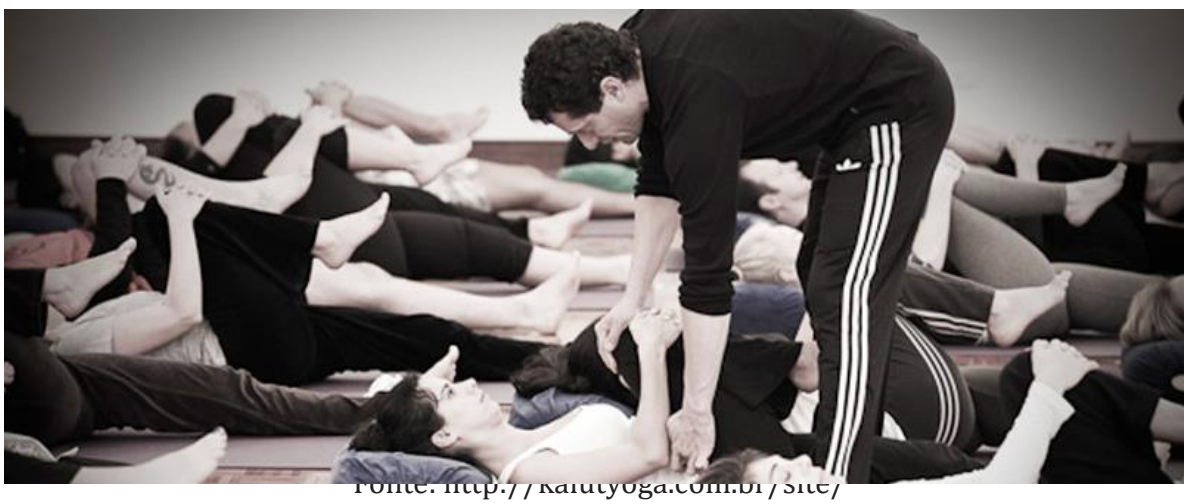

Nesse sentido, observamos alguns informantes recorrendo ao método em razão de motivações familiares: "A yoga apareceu na minha vida meio sem querer, fui acompanhar minha filha que estava interessada e me apaixonei."(Vera, 58 anos); e Luciana (26 anos), teve como motivação inicial o "Incentivo de familiar, que já era praticante". Assim como, há depoimento de participante que explora a interação social na Kaiut Yoga: "Na escola tenho encontrado amigos que não via a muitos anos, muito bom estes reencontros." (Vera, 58 anos). Fatos que comprovam que o consumo do objeto de estudo se correlaciona com a teoria dos grupos de referência, citada anteriormente e, mais do que isso, com o consumo como um integrador social (GARCÍA-CANCLINI, 1995).

Diante disso, podemos relacionar o consumo da yoga pelos pesquisados, sobretudo quando a motivações é de ordem familiar e integrativa social, com as crises das instituições sociais mais sólidas (BAUMAN, 2008) no contexto contemporâneo. Assim, reconhecemos a prática do consumo do serviço (e cultural) se transformando em alternativa de reconexão social mediada pela sociabilidade dos indivíduos. Para Martín -Barbero (2006) os sentidos e modos de uso social do discurso comunicacional que permeiam a construção e desconstrução do individual e do coletivo está inteiramente correlacionado com a socialidade - e como a família é um pilar importante pra compreensão do indivíduo.

Há, também, uma descrição sobre o status criado em cima da turma avançada, a qual o criador e líder do método é professor: "O que mais me chama a atenção é a diferenciação por parte dos alunos pelo status gerado ao frequentar a turma do Francisco 'turma avançada', é um tema 
que presenciei desde o começo, pois se assemelha a uma ascensão social." (Guilherme, 28 anos). Pode-se afirmar que participar das aulas que o Francisco é professor, se assemelha a uma "distinção social" (BOURDIEU, 2007), que em todo o grupo há o desenvolvimento de capitais que possibilitam que os atores se distinguam entre si, neste caso, gerando um status e reconhecimento entre os pares.

Imagens 4 e 5: Aulas das turmas avançadas

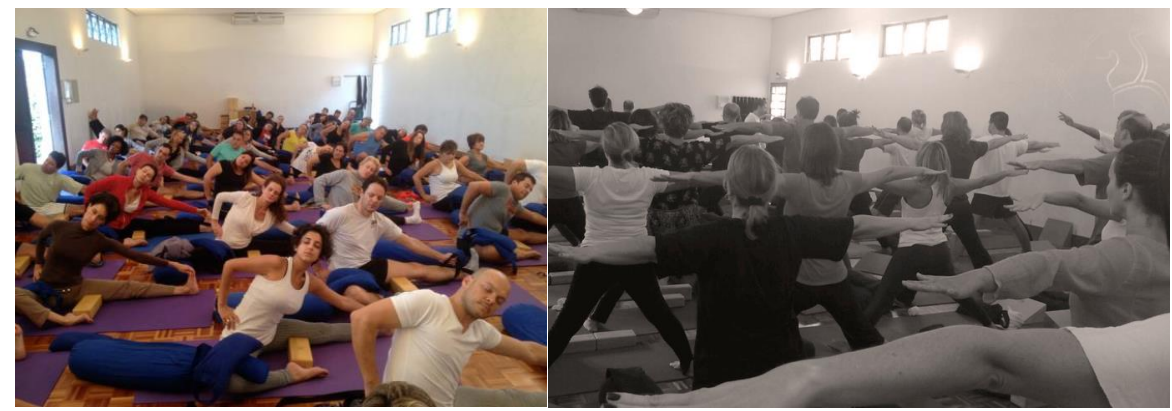

Fonte: http://kaiutyoga.com.br/site/

Portanto, pode-se complementar que o mercado espiritual e do bem estar é uma dimensão cada vez maior no espaço urbano contemporâneo por explorar valores intagíveis, como relacionamento com o outro, com uma comunidade, com um local de prática confortável e seguro e, no caso da Kaiut Yoga, uma experiência de instrospecção e consciência de si mesmo.

\section{Considerações finais}

A realização dessa pesquisa foi motivada pelo interesse em antropologia do consumo e pela curiosidade sobre os valores intagíveis no consumo de yoga. Se a pesquisa bibliográfica trouxe uma lucidez -e até mais amadurecimento - sobre os temas abordados (consumo cultural e ritual), a experiência etnográfica, a partir da observação participativa, juntamente com os relatos dos participantes do questionário, proporcionaram uma percepção in loco sobre o consumo de yoga.

Conseguiu-se observar como o consumo é cultural e influencia as referências e normas de pertencimento com determinados hábitos, além de embasar o argumento de aliar a visão antropológica para entender o 
universo de símbolos e signos desse espaço de interações socioculturais complexas que é o mercado do consumo. Com isso, fez-se essencial explorar os valores simbólicos dos rituais da prática da Kaiut Yoga. Apesar de ser um processo de consumo coletivo, a partir do discurso que parte dos professores, da divulgação, dos relatos coletados e até do próprio Francisco Kaiut, fica claro que público alvo do método Kaiut são indivíduos com vazios, dores e contextos pós-modernos.

No entanto, a partir dos relatos - e da perspectiva de Gárcia-Canclini (1995) e Martín-Barbero (2006) - pode-se afirmar que indivíduo ainda possui suas referências individuais de formação que o ancoram e, inclusive, o orientam em suas práticas de consumo, bem como, que os valores reconhecidos e incorporados pelos indivíduos também fazem parte no momento de significação dos bens materiais e simbólicos. Dessa forma, ressaltamos que, embora seja apenas ainda uma experiência etnográfica preliminar, já foi possível compreender que o consumo do método Kaiut de yoga - prática, liderança, signos e interação social serve como uma forma de reestabelecimento do indivíduo - pessoal ou coletivos - assim, vimos o consumo como um mediador social.

Os dados preliminares e exploratórios coletados, foram a afirmação externa das percepções observadas pela pesquisadora. Tanto que, com isso, pode-se até resolver uma questão antes apontada: sim, esse consumidor que pratica yoga busca o equilíbrio e a cura da dor, e esses tópicos ainda são os principais para uma motivação inicial - o consumo. Entretanto, a partir do embasamento da pesquisa como um todo, inclusive pelas entrelinhas dos relatos, esse indivíduo (pós)moderno (isolado) público alvo - se sente sim acolhido pelo grupo, por um líder, rituais periódicos, pela cultura e pelos símbolos com que ele se identifica, isto é, o consumo não é alienante e individualista, mas também serve para pensar (GARCÍA-CANCLINI, 1995) e, consequentemente, rearranjar a ordem social, bem como a a satisfação subjetiva dos sujeitos.

\section{REFERÊNCIAS}

BAUMAN, Z.. Vida para consumo: a transformação das pessoas em mercadoria. Rio de Janeiro: Zahar Ed., 2008.

BOURDIEU, P.. A Distinção: crítica social do julgamento, Porto Alegre, Editora Zouk, 2007. 
CAMPBELL,C.. A Orientalização do Ocidente: Reflexões sobre uma Nova Teodiceia para um Novo Milénio. Revista Religião e Sociedade. Rio de Janeiro, 1997.

DOUGLAS, M.; ISHERWOOD, B.. O mundo dos bens: para uma antropologia do consumo. Rio de Janeiro: Editora UFRJ, 2009.

DUARTE, J.. Entrevista em profundidade. In: DUARTE, Jorge; BARROS; Antonio (orgs.). Métodos e técnicas de pesquisa em comunicação. São Paulo: Atlas, 2009.

GARCÍA-CANCLINI, N.. Consumidores e cidadãos: conflitos multiculturais da globalização. Rio de Janeiro: Editora UFRJ, 2006.

HALL, S.. A questão multicultural. In: Da diáspora: identidade e mediações culturais. Belo Horizonte: UFMG, 2003.

KARSAKLIAN, E.. Comportamento do Consumidor. São Paulo: Atlas, 2000.

LAPLANTINE, F.. A descrição etnográfica. São Paulo: Terceira Margem, 2004.

MARTÍN-BARBERO, J.. Dos meios às mediações - comunicação, cultura e hegemonia. Rio de Janeiro, Editora UFRJ, 2006.

Ofício de cartógrafo: Travessias latino-americanas da comunicação na cultura. São Paulo: Loyola, 2004.

MOSCOVICI, S.. A Representação Social da Psicanálise. Rio de Janeiro: Zahar, 1978.

PERUZZO, M. C. K.. Da observação participante à pesquisa-ação em comunicação: pressupostos epistemológicos e metodológicos. In INTERCOM 2003. XXVI Congresso Brasileiro de Ciências da Comunicação.

PEIRANO, M.. Rituais ontem e hoje. Rio de Janeiro, Editora Jorge Zahar, 2003.

PULIDO, J. A. F.. Yoga, cuerpo e imagen: espiritualidad y bienestar, de la terapia a la publicidade. Bogotá. Universitas Humanística no.68, 2009

WOTTRICH, L. H.; SILVA, R. C; RONSINI, V. V. M.. A Perspectiva das mediações de Jesús Martín-Barbero no Estudo de Recepção da Telenovela. In: INTERCOM Sociedade Brasileira de Estudos Interdisciplinares da Comunicação; XXXII Congresso Brasileiro de Ciências da Comunicação, Curitiba, 2009. 